\title{
Pre-school Teacher Training and Management of Curriculum Implementation: A Case of Navakholo Sub- County, Kenya
}

\author{
Jacob Wambasi Kitari ${ }^{1}$ and Lydiah Wamocha ${ }^{2}$ \\ DOI: 10.29322/IJSRP.10.11.2020.p10730 \\ http://dx.doi.org/10.29322/IJSRP.10.11.2020.p10730
}

\begin{abstract}
Pre-school teacher training plays the role of inculcating management skills necessary for managing teaching and learning process in public Early Childhood Development Centres (ECDC). The main objective of this study was to establish the extent to which pre-school teacher training facilitate management of teaching-learning processs in public pre-schools. Pre-school teaching forms the backbone of the academic future for the beginning learners. This is achievable when teachers are adequately trained in curriculum implementation and management. Correlation research design was used to investigate the relationship between pre-school teacher training and management of teaching-learning process. The study targeted 176 teachers in charge and 268 pre-school teachers from 176 public pre-schools. Purposive sampling procedure was used to sample 81 pre-school teachers and 53 teachers in charge. Structured questionnaires were used to collect data from teachers in charge and teachers. According to the findings the certificate level of training produced the most effective teachers $3 \% 47.3$ as compared to those with bridging $3 \% 44.9$ and diploma $\$ \% 40.5$. On the basis of the findings, there is need to intensify pre-school teacher training programmes through inclusion of emerging paradigms like computer application and to review the ECDE teacher training curriculum for diploma course to make it more effective for the teachers to remain relevant on duty performance.
\end{abstract}

Index Terms- Training level, ECDE Teacher, Teaching/Learning process.

\section{INTRODUCTION}

$\mathrm{T}_{\mathrm{s}}$ eachers play a crucial role in facilitating the acquisition of learning skills among learners at all levels of Education. At the ECDE level, teachers play the role of laying the foundation for the learners to acquire basic literacy skills thus reading, writing and simple arithmetic. The efficiency of a teacher in facilitating the process of learning is influenced by teacher training amongst other factors. According to Dietrich \& Bruder, (2012), there is a positive relationship between pre-school teacher training and teaching-learning process. The Kenya Government recognizes the importance of ECDE in accelerating the attainment of one of the Millennium Development Goals (MDGs) which is provision of quality Basic Education for All (BEFA) (Republic of Kenya, 2006). It is from this basis that the Ministry of Education Science and Technology has given emphasis and opened opportunities for pre-school teacher training.

\section{Statement Of THE Problem}

The efficiency of a teacher in facilitating the process of learning is influenced by teacher training amongst other factors. According to Dietrich \& Bruder, (2012), there is a positive relationship between pre-school teacher training and management of the teaching-learning process. Despite the training of ECDE teachers, there seem to be a problem in children's attainment of basic literacy skills thus reading, writing and arithmetic skills. This was established via several studies conducted by UwezoKenya for example in 2010, Uwezo-Kenya, found that the level of literacy acquisition among pre-primary learners is seriously wanting because children completing pre-school level of learning could not read and understand simple English and Kiswahili sentences. They could also not manipulate simple arithmetic operations such as addition and subtraction. However, according to UNESCO, (2010) learners taught by effectively trained preschool teachers do not exhibit such weaknesses.

These issues raised eyebrows amongst stakeholders in ECDE concerning the relationship between pre-primary teacher training level and the management of curriculum implementation process in public pre-primary schools in Navakholo Sub-County, Kenya.

\section{LITERATURE REVIEW}

Teacher training programme has been defined by Fisher and Waideen, (1990) as a set of phenomena deliberately intended to prepare the teacher to deliver knowledge, skills, dispositions and norms required by the syllabus. The phenomena include lectures, seminars, field trips, practice of various kinds, models on specific topics, micro-teaching, observation in schools, tutoring individual trainees, peer-tutoring, examinations, screening procedures, social events among other aspects as provided by the curriculum of the programme (Dietrich \& Bruder, 2012).

Furthermore, Pre-school teacher training should be able to improve teachers' communication skills, professional attitudes, values and also equip the teacher with knowledge and the ability to identify and develop the education needs of the learners (Dietrich \& Bruder, 2012). This explains why governments across the world have Pre-school teacher training programmes. In line with this, the Government of Kenya regards "Academically and professionally qualified pre-school teachers as a prerequisite for provision of high quality and relevant education at all levels" 
(MOED-HRD \& UNICEF, 2009:146).The 2010 constitution of the Republic of Kenya chapter thirteen, Cap 237, has a provision for the Teachers Service Commission (T.S.C) to review the standards of education and training of persons entering the teaching service emphasising the legal framework as regards preschool teacher training programme. However, in spite of several reviews, it remains unclear why pre-school teachers are not yet meeting the expectations as regards teachers' service delivery; hence, the need for this study to evaluate the current pre-school teacher training levels in relation to the ability to manage ECDE Curriculum especially in public pre-primary Schools in Kenya. Providing consistent training across teacher education programmes is particularly challenging in the field Early Childhood Education due to lack of cohesive early childhood system in most countries (Winton, 2010). Although specific nations may have early childhood education programmes with particular training requirements for the teachers need, there is no internationally enforced standard for early childhood teacher education (Winton, 2010). This explains the diversity of, early childhood teacher training programmes. In Kenya, they include bridging, certificate and diploma courses offered through Subcounty Centres for Early Childhood Education (SCCECE) colleges.

Though Pre-school teacher training services have been offered in Kenya for long, the impact on service delivery especially in terms of the teachers' capacity to equip learners with reading, writing and arithmetic skills as well as its influence on management of syllabus implementation is far from perfection (Uwezo-Kenya, 2010). It is against this background that this study was developed to investigate how pre-school teacher training in Kenya impacts on the management of syllabus implementation.

Gardner (2003) noted that teachers are expected to perform syllabus implementation functions. However, according to a study by Taylor and Miels, (2012), early childhood teachers report management of syllabus implementation challenge as a predominant reason for stress and burnout among both teachers and learners. This explains the need for effective training and support in the management of ECDE syllabus implementation process. In particular, more attention needs to be paid to the type of training provided to the early childhood teachers (Dietrich \& Bruder, 2012). This qualifies the necessity of this study to identify training needs that are relevant to syllabus implementation in the Kenyan perspective. In order to guide the management of syllabus implementation effectively; pre-school teacher training programmes should include personnel preparation strategies that are based on appropriate professional standards. The standards include benchmarks for training in syllabus implementation management skills, learning assessment and other essential interventions like discipline management.

Syllabus implementation management skills should be focussed on proper understanding of the educational goals, aims and objectives (Taylor \& Miels, 2012). All interventions should address the understanding of teacher-learner relationships and supportive interactions as a foundation of pre-school teaching (Dietrich \& Bruder, 2012). The differences experienced in syllabus implementation process by pre-school teachers who have varying training levels, makes it necessary to ascertain the depth of training content offered at specific training level. This explains why this study was undertaken to assess the extent to which Kenyan ECDE teacher training facilitate syllabus implementation process.

\section{RESEARCH METHODOLOGY}

\section{Research Design}

In this study, correlation research design was adopted. This was because according to Mugenda and Mugenda, (2010) correlation research facilitates collection of data from an accessible population in order to determine the current status and relationship between the issues under investigation. In this case, the correlation facilitated collection of data related to the influence of teacher training on management of ECDE Curriculum implementation process. Correlation design was considered appropriate for this study because according to Kasomo, (2007), Mugenda and Mugenda, (2010) and Rubin et al., (2010), it ensures fair relationship of all sections of the target population.

\section{Sample Size}

According to Mugenda and Mugenda (2010 \& 2003) a large number of respondents is expected to yield a more reliable research findings because they indicate that correlation studies require a large sample of respondents in order to give reliable results. On the basis of this argument this research study used a sample size of 434 respondents distributed as indicated in Table 1.

Table 1: Sample Size Distribution

\begin{tabular}{|c|c|c|c|c|c|}
\hline Category & Bunyala West & Bunyala East & $\begin{array}{l}\text { Butsotso } \\
\text { North } \\
\end{array}$ & Total & $\begin{array}{l}\text { Percentage } \\
(\%)\end{array}$ \\
\hline Teachers & 27 & 27 & 27 & 81 & 30 \\
\hline Headteachers & 18 & 17 & 18 & 53 & 30 \\
\hline Total & 45 & 44 & 45 & 134 & \\
\hline
\end{tabular}

\section{Research Instruments: Structured Questionnaires}

Two different structured questionnaires were used to collect primary data. The first one gathered data from ECD teachers in charge and a second one from the pre-school teachers. They were considered appropriate for data collection because according to Njenga and Kabiru (2009) and Kothari, (2010) they facilitate 
controlled data collection since each item had predetermined multiple choices for the respondents to select from. This was further supported by the fact that according to Mugenda and Mugenda, (2010), the items in structured questionnaires are easy to analyze due to the presence of the multiple choices. During data collection each respondent was given a questionnaire to complete and return within a period of one week. Questionnaires return rate of $100 \%$ was achieved. A questionnaire for the teacher in charge had two sections. The first section captured background information about pre-school teacher training level, while, the second section had seven items that sought to correlate teacher training level and syllabus implementation aspects. A questionnaire for the pre-school teacher covered background information concerning the characteristics of the level of pre- school teacher training and the second part had questions on management of instructional materials and the delivery of basic literacy skills.

\section{Research Results and Discussion \\ Distribution of Respondents}

The distribution of teachers in terms of training levels was 26 at bridging course 33certificate and diploma 20 .

A sub group of 53 teachers in charge were targeted. The distribution of the ECD teachers in charge was 5 males and 48 females. In terms of training 9, 23 and 21 of the teachers in charge had bridging, certificate and diploma levels of training respectively. The distribution of respondents is shown in figure 1 .

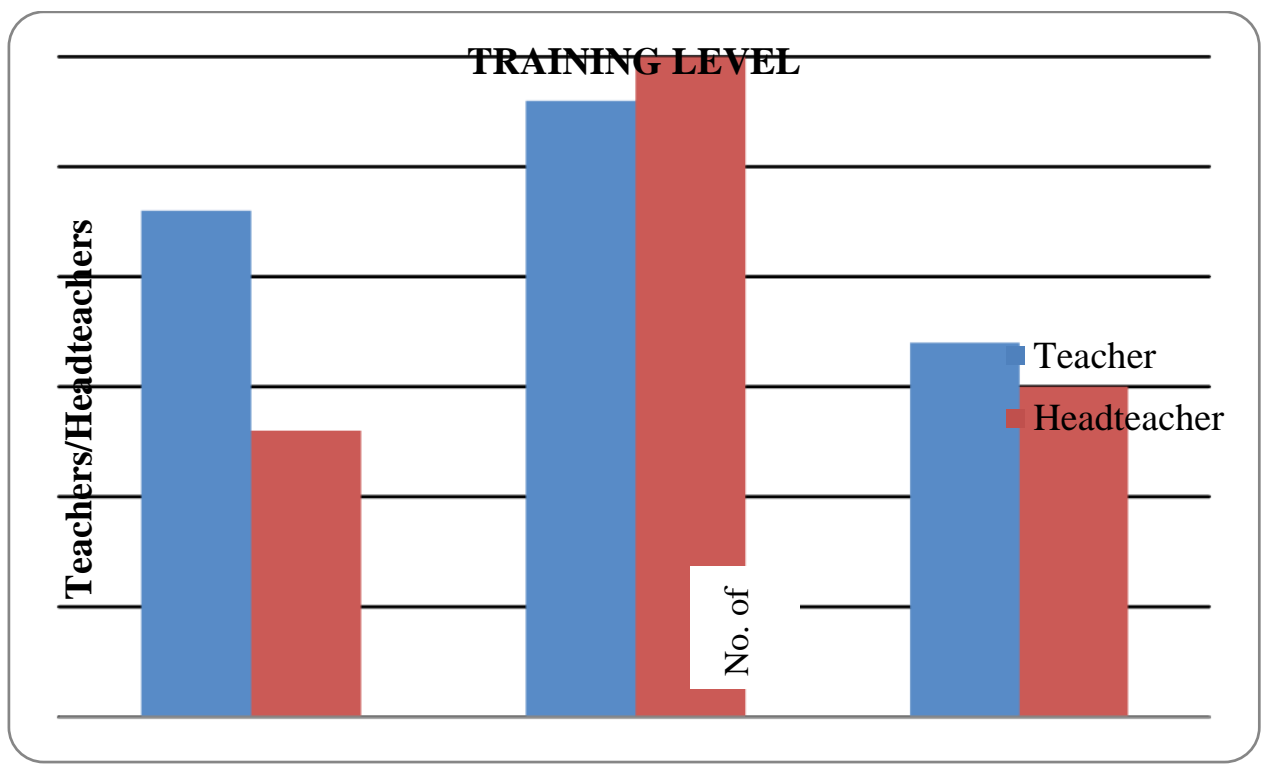

Figure1: Teacher Training Levels

Figure 1 revelaed that 26 ECDE teachers had a bridiging course, 33 had long course certifate and 20 teachers had attained diploma levels of training. The bridging course was meant to help teachers who had lower grade academically to secure an opportunity to serve the public as teachers in the beginner classes. Majority of the pre-primary teachers 33 started teaching with certificate level of training while those with diploma who are perceived to have acquired the highest level of training within the researcher's area of jurisdiction were very few thus 20.Teachers in charge were also asked to state their level of training at the time they started teaching in their respective stations. The results revealed that 13 of them started the teaching career with a grade of short course.

Teachers in charge who joined their career of imparting knowledge, skills and attitudes into the learners with a professional development level of certificate were the majority represented by 76 . Last but not least only 15 teachers in charge were previleged to start the teaching fratenity with a higher level of training thus diploma in early childhood development and education. This group of managers are expected to perform slightly better than those with the lower cadre of training.
Table 2: Teachers Current Professional Qualification

\begin{tabular}{llllll}
\hline Bridgin \\
g
\end{tabular}

The study findings revealed that there were 26 ECDE teachers with a professional grade of a short course (Bridiging course) and 9 teachers in charge had the same qualfiiaction of bridiging course. The study area had a majority number 33 ECDE teachers with a training level of certificate. There were 23 teachers in charge with ECDE certificate grade. This indicated that most ECDE centres were under the management of certfiicate holders. A few ECDE centres had 20 teachers and 19 teachers in charge with professional qualification of a diploma in ECDE.

\section{Management of ECD Syllabus Implementation Process}

All over the world, Syllabus implementation is perceived as a critical factor in effective teaching/learning services (Alvarez, 
2007). In fact, it is one of the challenges that affect the delivery of quality teaching services in most public ECDE centres in Kenya. It is against this background that this study was formulated to assess the relationship of Pre-school teacher training and management of syllabus implementation process. The study specifically covered the bridging course, certificate course and diploma training levels which was implemented in form of two years in-service programme. This focus was informed by the fact that most of the serving ECDE teachers had attained these levels of training. The pre-school teachers in charge being the officially designated managers of the curriculum implementation process as per the existing policy guidelines were the school personnel accessible to information regarding pre-school teacher training and management of ECDE syllabus implementation process, hence, the suitable sources of information with regard to this specific objective of the study.

The findings of the study were as indicated in Table 3.

Table 3: Pre-school Teacher Training levels and Management of curriculum Implementation

\begin{tabular}{|c|c|c|c|c|}
\hline Syllabus implementation Aspect & Bridging & Certificate & Diploma & Average \\
\hline Delivery of Arithmetic skills & 43.4 & 50 & 51 & 47.3 \\
\hline Curriculum interpretation Accuracy & 39.10 & 50 & 44.4 & 44.9 \\
\hline Delivery of reading skills & 47.8 & 46.5 & 25 & 40.5 \\
\hline Improvement of reading skills & 47.8 & 33.4 & 25 & 36.1 \\
\hline Delivery of writing skills & 47.8 & 31.3 & 25 & 34.7 \\
\hline Improvement of writing skills & 26 & 45 & 27.8 & 32.6 \\
\hline $\begin{array}{l}\text { Efficiency of } \\
\text { implementation }\end{array}$ & 26 & 30 & 33.3 & 29.4 \\
\hline Average & 40.4 & 47.3 & 33 & \\
\hline
\end{tabular}

\section{Source: (Field Data, 2014)}

Analysis of the results revealed that certificate level of teacher training had the highest mean score amongst the seven aspects of syllabus implementation aspects covered in the study as indicated by a mean score of $47.3 \%$. The results showed that certificate level of pre-school training was more suitable than the other levels of training. It was followed by bridging course with a mean score of $40.4 \%$ while diploma training had the lowest mean score of $33 \%$. The gap between scores attained by teachers who had the bridging and certificate levels $(47.3 \%>40.4 \%)$ was attributed to the idea that pre-school teacher training at certificate level is more enriched in terms of the necessary knowledge and skills, hence, more effective in curriculum implementation than that for bridging level of training which is also an academically lower level. This was in line with the findings of Kodak, (2011) according to whom higher training levels are more suitable than lower levels. The Certificate level of training also scored higher than diploma training level. This might have been due to the differences in the relevance of the syllabi of certificate and diploma teacher training programmes with the certificate syllabus being more appropriate and effective. This is contrary to the report of Godia, (2005) according to which advancement in teacher training levels are expected to directly correlate with increase in appropriateness and effectiveness in duty performance.

Further analysis of the results indicated that teacher training levels exhibited different degrees in regard to ECDE syllabus coverage. Delivery of arithmetic skills was the most significant aspect as justified by the respondents' mean score of $47.3 \%$. It was equally noticed in both certificate and diploma levels of training $50 \%$. The set level of significance was at alpha 0.05 whereby in case the coefficient score is more, the null hypothesis will be rejected and if it is less, the null hypothesis will not be rejected. From the above analysis the researcher rejected the null hypothesis which states that there is no statistically significant relationship between various levels of ECD teacher training syllabi. However, comparatively bridging teacher training had a lower mean $43.4 \%$. This was attributed to the idea that the teacher training syllabus at this stage was relatively inferior and ineffective relative to delivery of arithmetic skills to the ECDE learners.

Accuracy of curriculum interpretation was the second variable in regard to syllabus coverage with a mean score of $44.9 \%$. The gap $(47.3 \% .>44.9 \%)$ in the mean scores on delivery of arithmetic skills and the accuracy of curriculum interpretation was attributed to the skewness of the teachers training programmes towards instilling basic arithmetic skills at the expense of the accuracy of curriculum interpretation and implementation in all teaching subject areas.

Certificate teacher training had the highest mean on accuracy of curriculum interpretation $50 \%$ followed by diploma $44.4 \%$ and then bridging level came third with a mean score of $40.5 \%$. The results indicated that the syllabus for certificate level of training pre-school teachers was more suitable for the ECDE syllabus implementation relative to interpretation and by 
extension service delivery followed by that of Diploma and then bridging level.

Alternatively, the bridging course syllabus lacked the capacity to facilitate interpretation of the ECDE syllabus while that of diploma level of training was too advanced relative to the ECDE syllabus demands and learning needs of ECDE children. The level of performance by the diploma trained teachers could also be because the syllabus is more inclined towards management than practical teaching that calls for accurate syllabus interpretation. Similar findings were established by Merrel, (2010), who observed that as teachers advance in professional development, they relax and reduce their output.

Another aspect of syllabus implementation was delivery of reading skills with a mean score of $40.5 \%$. The gap $(44.9 \%>$ $40.5 \%$ ) between accuracy in curriculum interpretation and delivery of reading skills was attributed to the fact that teacher's capacity to impart reading skills to the learners was founded on accuracy of curriculum interpretation. This is in accordance with Godia, (2005) according to whom the capacity of the teacher to interpret the syllabus was both a pre-cursor and determinant of the capacity to deliver reading skills hence the lower score on delivery of reading skills.

Further analysis of the results revealed that teacher training levels enhances delivery of reading skills. From the analysis scores from different levels of training decreased with advancement in training levels. This was justified by mean scores of $47.8 \%$, $46.5 \%$ and $25 \%$ for bridging course, certificate, and diploma levels respectively. This was attributed to the fact that the syllabi for higher levels of pre-school teacher training tended to exclude or significantly minimized the coverage of the fundamentals of reading skills which are critical literacy requirements for the ECDE learners (Fox et al., 2010). The results further indicated that the exclusion increased more significantly between certificate and diploma levels. This was duly justified by the wideness of the gap between the respective mean score levels $(46.5 \%>25 \%)$. This finding is in line with the report of the MOEST, (2006) which recommended scaling up or upward review of teacher training syllabi to enhance teacher preparedness for better competencies at the work place.

Comparatively, analysis of the results showed that preschool teacher training on improvement of the learner's reading skills was lower than that of the delivery of reading skills $(36.1 \%$ $<40.1 \%$ ). This indicated that though it is easy for teachers to deliver basic reading skills for simple reading exercises, improving the capacity of the learners for more complex reading demands is still a challenge to the ECDE teacher training interventions. This was attributed to limitations in content and focus of all levels of ECDE teacher training (Pribble, 2013). A deeper analysis of the results further revealed that teacher training interventions decreased as one advances up the teacher training levels as indicated by mean scores of $47.8 \%, 33.4 \%$ and $25 \%$ for bridging course, certificate and diploma levels respectively. This is contrary to MOE report of 2005 according to which advancement in training should lead to progressive improvement in service delivery. These results could also be accounted for by the fact that advancement in training levels was accompanied with reorientation towards management concerns at the expense of curriculum implementation inclusive of improvement of learners' reading skills.
There was also a significant relationship between delivery of writing skills and syllabus intervention with a mean score of $35.4 \%$. The narrow gap $(36.1 \%>35.4 \%)$ between the two syllabus aspects was attributed to the fact that the basic academic demands for improvement of reading skills and delivery of writing skills were similar. Further analysis of the results indicated that teacher training on delivery of writing skills decreased as one advanced from bridging through certificate to diploma training levels as indicated by mean scores of $47.8 \%, 31.3 \%$ and $25 \%$ respectively. This was attributed to the fact that higher teacher training levels excluded topics on the fundamentals of writing or only had limited content.

The next aspect of teacher training that followed was that on teachers' capacity to improve the children's writing skills which had a mean score of $32.6 \%$. However, the trend of relationship between teacher training and improvement of writing skills was unique when compared to other study aspects. This was because the scores increased significantly as one advanced from bridging to certificate level $(26 \%<45 \%)$ and dropped significantly from certificate to diploma levels $(45 \%>27.8 \%)$. The trend indicated certificate level of training to be the optimum level for improvement of the ECDE learners' writing skills. The lower score realized by the bridging when compared to that of certificate level of teacher training was attributed to the idea that the content and design of the syllabus for bridging course was too basic to facilitate advancement of these skills at the same time the diploma syllabus was not adding value for the same practice. Similar results were established by Brown (2008) who observes that authorities should always strive to select suitable content and syllabus for training purposes.

Among the aspects of syllabus interpretation and implementation covered in the study, efficiency of curriculum implementation had the least mean by teachers' training level with a score of $29.4 \%$. This indicated that all ECDE teachers' training interventions had serious weaknesses since efficiency in the implementation of the ECDE curriculum is the basic indicator of the adequacy of the content for teachers' training. A deeper analysis of the results indicated that though below average, the scores of teacher training levels increased as one shifts from bridging through certificate to diploma levels $(25 \%<30 \%$ $<33.3 \%$ ). This trend was attributed to the idea that the teachers' training helps teacher trainees to perfect their management skills which are more suitable relative to syllabus interpretation as one advance in professional development. These results are in tandem with the findings of Godia, (2005) according to whom advancement in training levels progressively translates into better service delivery.

\section{Hypothesis Testing}

When the results of this objective were subjected to hypothesis testing using Pearson's moment correlation coefficient, the findings were as in table 4. 
Table 4: Results of Hypothesis test

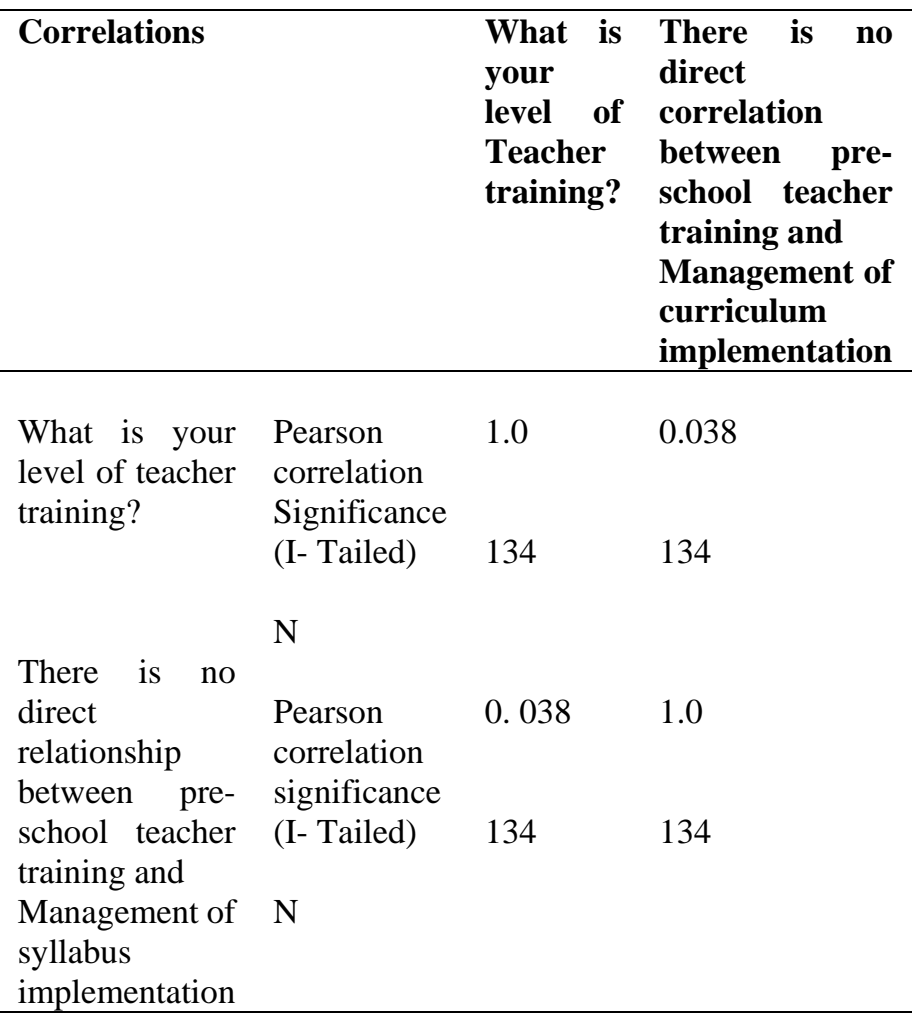

When the findings of this research study were subjected to one way analysis of variance (ANOVA) to evaluate the relationship between Pre-school Teacher Training levels and Management of Syllabus Implementation in Navakholo subcounty, the results were $\quad \mathrm{F}(2,53)=4.13, \mathrm{P}=0.04$.

According to the findings, the relationship between teacher training levels and management of curriculum implementation has a correlation coefficient of 0.04 (Pearson's product moment correlation coefficient score). In this study the set alpha level for rejection of null hypothesis was 0.05 . From the assessment of the coefficient score the researcher rejected the null hypothesis which states that there is no significant relationship between teacher training levels and management of ECDE syllabus implementation. This rejection indicates that pre-school teacher training levels are statistically significant in relation to management of syllabus implementation.

\section{CONCLUSION AND RECOMMENDATION}

\section{Conclusion}

The study examined the correlation between pre-school teacher training and the application of management skills in public pre-primary centres. What emerged was that Certificate level of teacher training had better knowledge of ECDE curriculum interpretation and implementation with a mean of $47.3 \%$. The bridging course had a lesser mean of $40.4 \%$ while the diploma level had the least average score of $33 \%$. It revealed that certificate level of training enhanced a high level of interactive teaching with the learners which proved more effective compared to other levels of training. The diploma level of training produced the least effective ECDE teachers in terms of curriculum implementation.

\section{Recommendation}

On the basis of the findings of the study, there is need to review the quality of training for diploma ECDE teachers in order to manage emerging dynamics in the management of pre-school teaching/learning process.

\section{REFERENCES}

[1] Dietrich,V. \& Bruder,H. (2012). Prevention and intervention with young children's challenging behaviours. A summary of content knowledge, 32, 29-49 and the trajectory of children's school outcomes through eighth grade. Child development, pp.72, 625-638.

[2] Downer., J.C. \& Willford, P. (20011). Preschool peer interactions and readiness to learn: peer play and learning behaviours. Journal of Educational Psychology,pp. 92, 450-

[3] EFA FTI (2000). Global and Regional Activities (GRA). Thematic Area Learning Outcomes. New York: Stockholm university press.

[4] Fisher, P. R. \& Wideen, F.M. (1990). Research in Teacher Education. International

[5] Perspectives. London: The Flamer Press.

[6] Frederick, R. (2009). Teachers Transforming Thinking on Issues of Social Justice.

[7] New York: The McGraw Hill Company

[8] Fox, L., Strain, P.S \& Hemmeter, M.L. (2010). Response to intervention and pyramid model. Infants and young children, pp. 23, 3-5.

[9] Hainstock, E.G. (2011). The Essential Montessori. New York: Plume Publishing.

[10] Hansford, A. (2010). The behaviour analyst today, pp. 20, 59, 80.

[11] Hapman, C. (2009). Quality and Qualification: Links between professional development and Quality in early care and education settings in M. Zaslow \& I. Martinez-Beck (Eds.), Critical issues in early childhood professional development (77-110). Baltimore: Brookes.

[12] Humphrey, N.(2011). Teachers' Judgements of problems in the transition to kindergarten. Early childhood Research. pp. 15, 147-168.

[13] Ishiun, T. (2009). Linking brief functional analysis to intervention design in general education settings. The Behaviour Analyst Today pp. 10, 47-53.

[14] Kabiru, M. and Njenga, A. (2009). Research Monitoring and Evaluation. Nairobi: Focus Publishers.

[15] Kasomo, D. (2007).Research Methods. Nairobi: Jomo Kenyatta Foundation Publishers.

[16] Kodak,T. (2011). Functional assessment of instructional variables: Linking assessment and treatment. Research in young children, pp. 5,1059-1080.

[17] Kothari, C .R. (2010). Research Methodology, Methods and Techniques (Second Revised Edition). New Delhi: New age international (Ltd, Publishers).

[18] Loice M. Pribble (2013).Early Childhood Teachers' knowledge Assessment and intervention Practices. University of Oregon: Oregon University Press.

[19] London, E. (2010). Teaching Reading England: Oxford University Press.

[20] Lovett, M.P. (2003) Improving the Quality of Basic Education in SubSaharan African. Paris, France: ADEA

[21] Margolin, J.B. (2002). Teaching Young Children at School and Home. New York: Macmillan Publishing Co. Inc

[22] Marshack, H. (2007). How Children Develop and Grow. U.S.A: Washington State Bar Association and Word problem Solving Skills. German: University of Bayreuth press.

[23] Menzies,H. \& Lane, K.L.(2011).Using self regulation strategies and functional assessment-based interventions to provide academic and behavioural support to learners. Preventing school failure: Alternative Education for Children and Youth, pp.55,181-191.

[24] Merrell, K.W. (2010). Better Methods, Better Solutions: Developments in school-based, behavioural assessment. School Psychology, pp. 422 426.Review, 39, 
[25] Ministry of Education and Human Resources Development and UNICEF (2009) Comprehensive Education Sector Analysis Report. Nairobi: Government Printers.

[26] Ministry of Education Science and Technology, (2006). Improving Training for Effective Teaching. Nairobi. Government Printers.

[27] Ministry of Education Science and Technology, (2005). A Policy Framework for Education, Training and Research Sessional Paper No. 1 of 2005) Nairobi: Government Printers.

[28] Ministry of Education, (2006). Diploma Teacher Training Syllabus. Nairobi. Government Printer.

[29] Mugenda, O.M \& Mugenda, A.G. (2010) Research Methods; Qualitative \& Quantitative Approaches Nairobi: Acts Press

[30] Mugenda, O.M \& Mugenda, A.G. (2003) Research Methods; Qualitative \& Quantitative Approaches Nairobi: Acts Press

[31] Nadiv, T. (2011).Predictors of pre-school children's compliance behaviour in early childhood classroom settings. Journal of Applied Developmental Psychology, pp.25,439-457.

[32] Ndiku, M.J. (2007).Strategic Management: A New Knowledge Base for School Reforms in School-based Management. The Educator, vol.1 No.4. A journal of the school of Education; Moi University press.

[33] Republic of Kenya,(2006). Early Childhood Development and Education Policy Framework. Nairobi: Government Printer

[34] Rittle. Johnson and Siegler (2008). Contemporary Mathematics Construction. Licon: University of Nebrasha Press.

[35] Rubin, A. (2010).Classroom instruction: Background, assumptions and challenges. Journal of Early Intervention, pp. 33,(4), 371-380.

[36] Rubin, A., \&Babbie,E(2nd Ed.)(2010).Essential Research Methods for Social Work pacific Grove, CA:Brooks| Cole.
[37] Scarcella, M. \& Oxford, D. (2008). Writing Skills in Early Years. London. Oxford University Press

[38] Schoppek, J.\& Tulis, F. (2009). An Activity-Based Approach to Developing Young Children's Literacy Comptence. Baltimore: Paul Brookes.

[39] Sifuna, D. (2007) Teachers' Status on Pay and Training. Nairobi: UNESCO.

[40] Stoughton,E.H.(2007).Pre-service teachers reflect on classroom management. Teaching and Teacher Education, pp. 23, 1024-1039.

[41] Taylor, K. \& Miels, J. (2012).The role of teacher efficacy in strengthening classroom support for pre- school children. Early Childhood Education Journal,pp. 40, 135-146.

[42] UNESCO,(2010).Teachers' status on pay and training. New York: UNESCO

[43] UNESCO,(2008).Moving Towards Universal Primary Education and Literacy. New York: UNESCO

[44] UNESCO,(2007).Moving Towards Universal Primary Education and Literacy. New York: UNESCO

[45] Uwezo-Kenya,(2010). Scaling Basic Literacy in Lower Primary.Nairobi:Longhorn publishers

[46] Winton, P. (2010).Professional development and quality initiatives: Two essential components of an early childhood system. The quest for quality: promising innovations for early childhood programmes, pp 113-130.

\section{AUTHORS}

First Author - Jacob Wambasi Kitari. kitarijacob@gmail.com Second Author - Lydiah Wamocha, lwamocha@mmust .ac.ke 